\title{
PLASMA LENS FOR ELECTRON AND POSITRON BEAMS
}

\author{
D.S. Bondar ${ }^{1,2}$, V.I. Maslov ${ }^{1,2}$, I.N. Onishchenko ${ }^{1}$, R.T. Ovsiannikov ${ }^{2}$ \\ ${ }^{1}$ National Science Center “Kharkov Institute of Physics and Technology”, Kharkiv, Ukraine; \\ ${ }^{2}$ V.N. Karazin Kharkiv National University, Kharkiv, Ukraine \\ E-mail:vmaslov@kipt.kharkov.ua
}

Focusing of both electron and positron bunches in electron-positron collider is necessary. When long electron/positron bunch is injected into the plasma, the focusing force is not uniform but oscillated. It is shown that a long positron bunch after focusing is destroyed faster than an electron bunch due to betatron and plasma oscillations.

PACS: 29.17.+W; 41.75.LX

\section{INTRODUCTION}

Plasma wakefield accelerators provide an extremely high accelerating gradient $[1-13]$, long sequence focusing and large transformer ratio obtaining [14 - 23], resonant wakefield excitation by a nonresonant sequence of electron bunches [24, 25]. Focusing of relativistic electron bunches by wakefield, excited in the plasma, is important previously studied effect [26 - 37]. Mechanism of focusing in the plasma, by which all bunches of a sequence are focused identically and uniformly, is proposed and investigated by numerical simulation in [14 - 16].

The plasma lens for long relativistic electron and positron bunch focusing is studied in this paper by numerical simulation using code lcode [38]. Unbounded non-magnetized homogeneous plasma is considered. The Gaussian $\left(\cos ^{2} A\right)$ in longitudinal direction bunch (current profile) is considered.

The purpose of this paper is to show by numerical simulation that one can achieve conditions of focusing of long relativistic electron and positron bunch. In this paper the authors present the results of numerical simulation on the focusing force distribution for long electron and positron bunches.

We use the cylindrical coordinate system $(r, z)$. The time $\tau$ is normalized to $\omega_{p e}^{-1}$, all the distances and coordinate $\xi$ - to $c \omega_{p e}^{-1}$, the density - to the unperturbed plasma electron density, the beam current $I_{b}-$ to $m c^{3} / e=17 \mathrm{kA}$, the fields - to $m c \omega_{p e} / e$, where $m$ is the electron mass, $e$ is the electron charge, $c$ is the speed of light, $\omega_{p e}$ is the plasma electron frequency. $\lambda$ is the plasma wavelength. The simulation time is $60.1 \omega_{p e}^{-1}$. $\gamma_{b}=5$ for all bunches. The length of all bunches is $L_{b}=8 \lambda$. These normalisations are used also in the Figures. The arrow on all Figures indicates the direction of movement of the bunches.

We present the numerical simulation data on plasma wakefield excitation by a relativistic electron and positron bunch, obtained with the $2.5 \mathrm{D}$ quasi-static code lcode. It treats the plasma as a cold electron fluid (magnetohydrodynamics model), and the bunches as ensembles of macro-particles.
Spatial step equals $0.1 c \omega_{p e}^{-1}$. Time step for plasma electrons equals $0.1 \omega_{p e}^{-1}$. Time step for beam electrons equals $0.1 \sqrt{\gamma_{b}} \omega_{p e}^{-1}$. Spatial dependences in selected points of observation are presented.

\section{RESULTS OF NUMERICAL SIMULATION}

At first, the excited field distribution, formed by long Gaussian electron bunch in the plasma (Fig. 1) is considered.

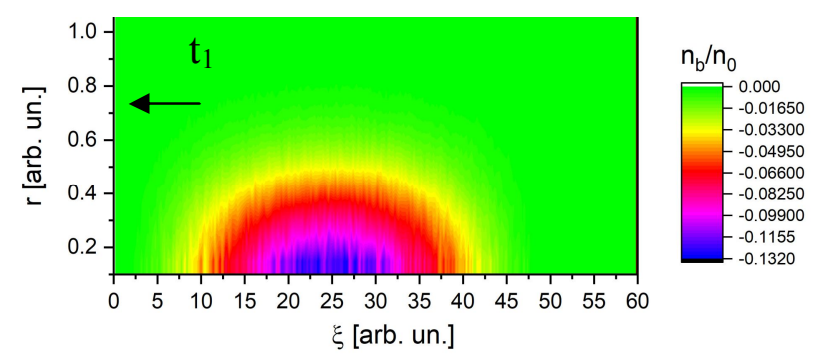

Fig. 1. Spatial distribution of Gaussian bunch electron density $n_{b}(\xi, r)$ (minus indicates to the electron

bunches) at $\gamma_{b}=5,2 \sigma_{z}=25, \sigma_{r}=0.1$, maximum initial electron bunch current $I_{b}=0.6 \cdot 10^{-3}$

In this case, a rather smooth electrons $n_{e}(\xi, r)$ (Fig. 2) density pit is formed in the plasma in the Gaussian bunch region.

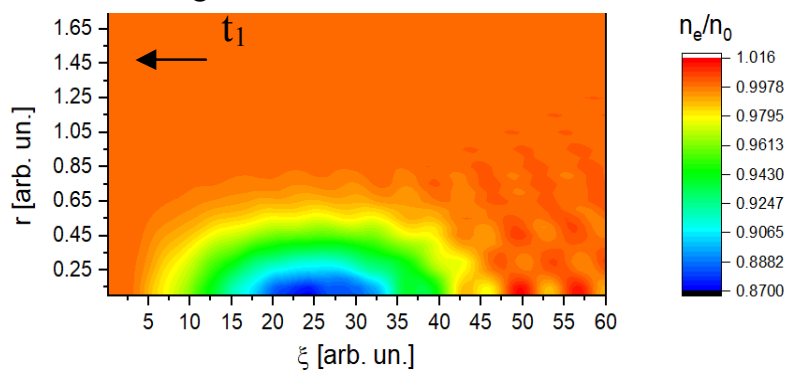

Fig. 2. Spatial distribution of plasma electron density $n_{e}(\xi, r)$ (corresponds to Fig. 1)

In addition, smooth focusing force is observed in the region of the bunch (Fig. 3).

First (approximately, during the first half of the simulation time), the focusing of the electron bunch is observed (Figs. 4-6). The centers of the bunches are subjected to the strongest focusing (see Fig. 5). 


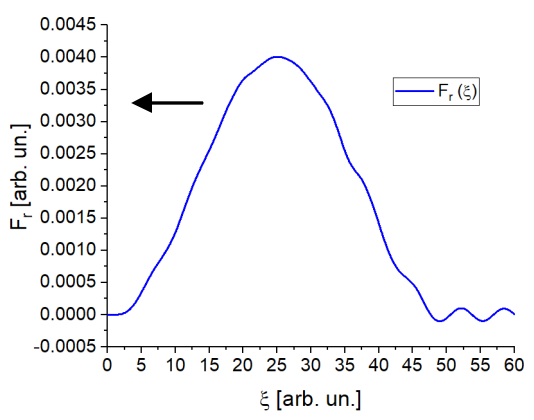

Fig. 3. Longitudinal distribution of focusing force $F_{e}(\xi)$ (corresponds to Figs. 1, 2)

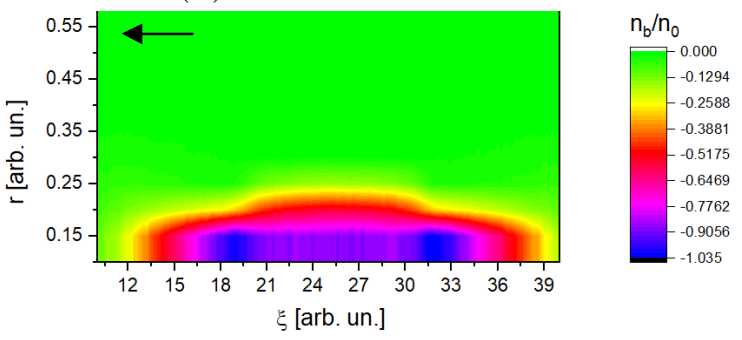

Fig. 4. Spatial distribution of focused Gaussian bunch electron density $n_{b}(\xi, r)$

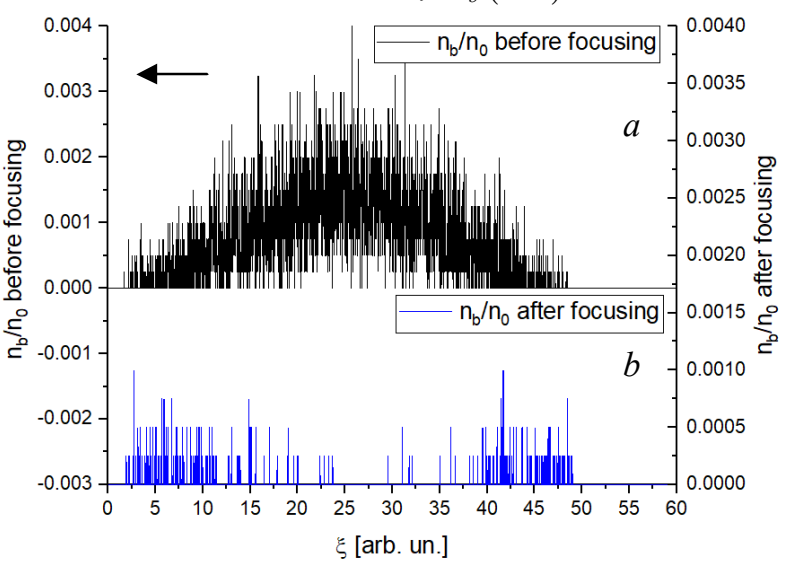

Fig. 5. Longitudinal distribution of bunch electron density $n_{b}\left(\xi, r=r_{b}\right)$ : before focusing (a); after focusing (b)
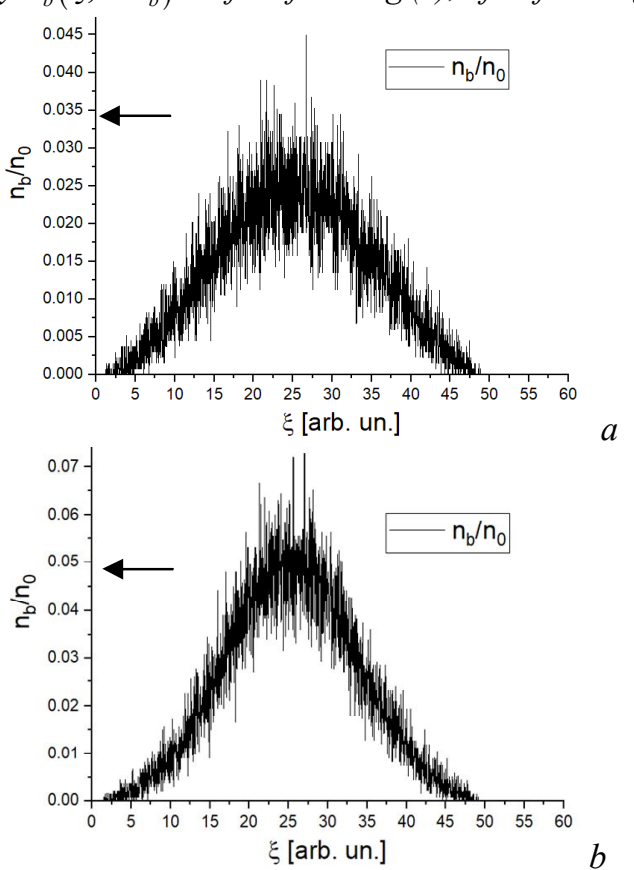

Fig. 6. Longitudinal distribution of bunch electron density $n_{b}(\xi, r=0)$ : before focusing (a); after focusing (b)
Then (after approximately $t=30 \omega_{p e}^{-1}-40 \omega_{p e}^{-1}$ ) betatron oscillations develop. Since the frequency of betatron oscillations for electrons of the bunch located at different radii is different, the bunch stratifies and the electrons of the bunch peripheral along the radius are defocused (Fig. 7). In general, the destruction of the bunch can be observed along the entire diameter.

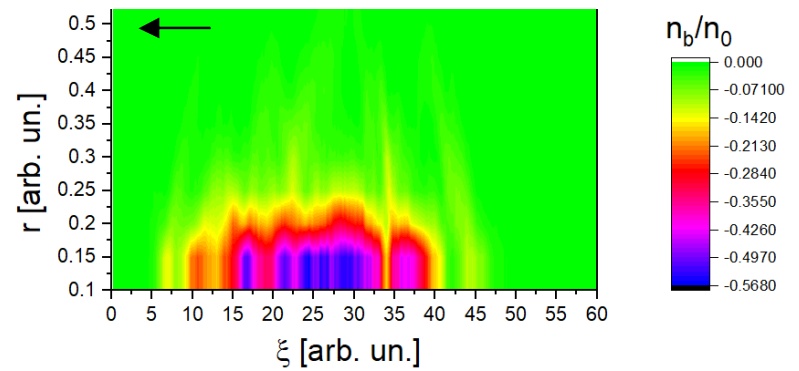

Fig. 7. Spatial distribution of Gaussian bunch electron density $n_{b}(\xi, r)$ due to betatron and plasma oscillations

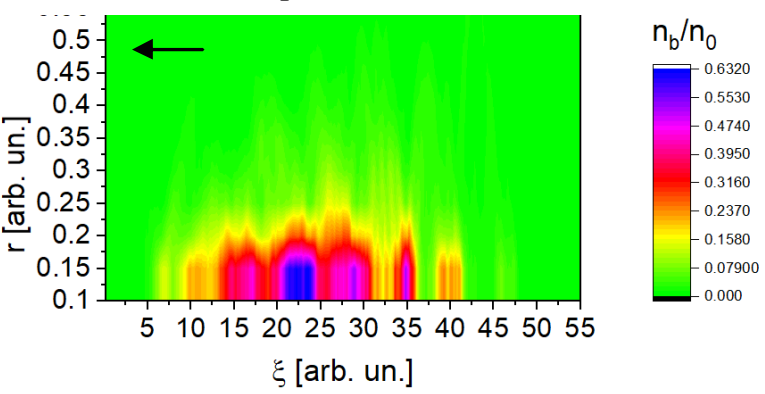

Fig. 8. Spatial distribution of Gaussian bunch positron density $n_{b}(\xi, r)$

From comparison Figs. 7 and 8 it can be seen that for the same time the positron bunch is destroyed more strongly than electron.

From the beginning, oscillations are observed in the second part (after $\xi=30 \mathrm{c} / \omega_{p e}$ ) of the plasma electron density pit (Fig. 9).

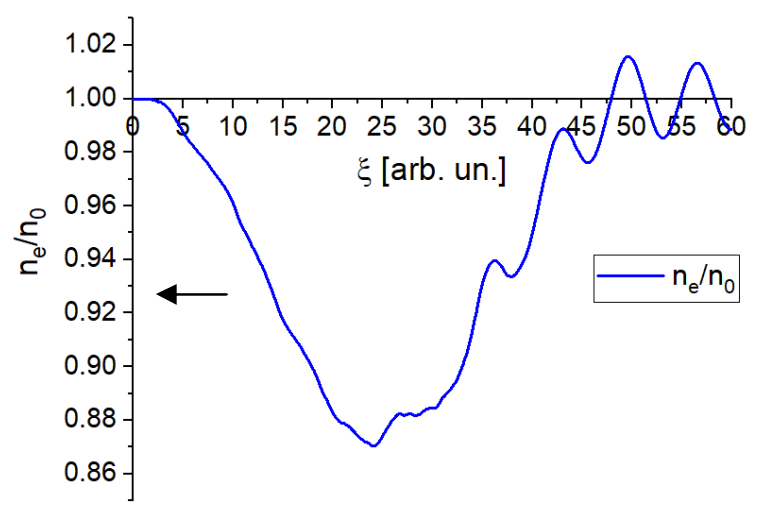

Fig. 9. On-axis longitudinal distribution of plasma electron density $n_{e}(\xi, r=0)$ (corresponds to Figs. 1, 2)

Then oscillations are excited in the plasma electron density (Fig. 10).

The development of oscillations can be seen on $F_{r}(\xi)$ graph (Fig. 11).

As a result, the bunch is modulated (see Fig. 12). 


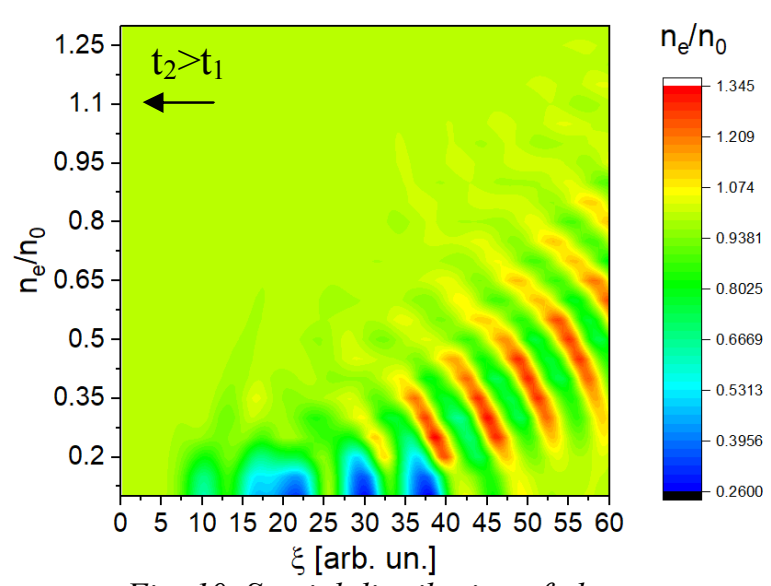

Fig. 10. Spatial distribution of plasma electron density $n_{e}(\xi, r)$

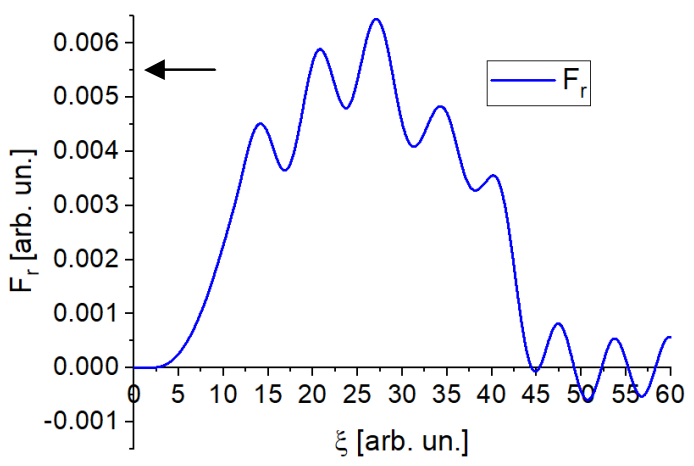

Fig. 11. Longitudinal distribution offocusing force $F_{r}(\xi)$

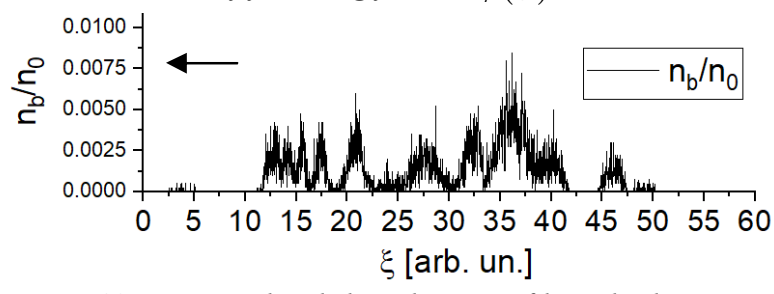

Fig. 12. Longitudinal distribution of bunch electron density $n_{b}\left(\xi, r=r_{b}\right)$ at large (end of simulation) times

In general, the destruction of the bunch is visible along the entire diameter. Thus, the inhomogeneity of the focusing force and the modulation of relativistic bunches of electrons and positrons during their propagation in the plasma due to betatron and plasma oscillations are shown. In addition, it has been shown that positron bunch is destroyed more strongly and faster than electron bunch.

\section{CONCLUSIONS}

A numerical simulation of the focusing of electron and positron bunches by a plasma lens is carried out. When a long electron/positron bunch is injected into the plasma, the resulting focusing force is not uniform, but oscillates. It was shown that a long bunch of positrons after focusing is destroyed faster than an electron bunch due to betatron and plasma oscillations.

\section{ACKNOWLEDGEMENTS}

The study is supported by the National Research Foundation of Ukraine under the program "Leading and Young Scientists Research Support" (project \# 2020.02/0299).

\section{REFERENCES}

1. E. Esarey, S. Sprangle, J. Krall, A. Ting. Overview of Plasma-Based Accelerator Concepts // IEEE Trans. Plasma Sci. 1996, v. PS-24(2), p. 252-88.

2. A.V. Brantov, T.Zh. Esirkepov, M. Kando, H. Kotaki, V.Yu. Bychenkov, and S.V. Bulanov. Controlled electron injection into the wake wave using plasma density inhomogeneity // Phys. Plas. 2008, v. 15 , p. 073111.

3. S. Lee, T. Katsouleas, R. Hemkel, and Mori. W2000 Simulations of a meter-long plasma wakefield accelerator // Phys. Rev. E. 2000, v. 61(6), p. 7014-21.

4. N. Kumar, A. Pukhov, K. Lotov. Self-modulation instability of a long proton bunch in plasmas // Phys. Rev. Lett. 2010, v. 104(25), p. 255003.

5. P. Muggli et al. E-157: A plasma wakefield acceleration experiment // SLAC-PUB-8656. 2000, p. 1-6.

6. M. Hogan et al. Multi-GeV Energy Gain in a Plasma-Wakefield Accelerator // Phys. Rev. Lett. 2005, v. 95 , p. 054802.

7. I. Blumenfeld et al. Energy doubling of $42 \mathrm{GeV}$ electrons in a metre-scale plasma wakefield accelerator // Nature. 2007, v. 445(7129), p. 741-44.

8. V.V. Tsakanov. On collinear wake field acceleration with high transformer ratio // NIMA. 1999, v. 432(23), p. 202-13.

9. A. Marocchino et al. High Brightness Electron Beams from Plasma-Based Acceleration // LINAC2018. (Beijing: China), p. 637.

10. M.C. Thompson, J. Rosenzweig, H. Band Suk. Plasma density transition trapping as a possible high-brightness electron beam source // Phys. Rev. Spec. Top. Accel. and Beams. 2004, № 7, p. 011301.

11. K.V. Lotov, V.I. Maslov, I.N. Onishchenko, and E.N. Svistun. Simulation of plasma wakefield excitation by a sequence of electron bunches // Problems of Atomic Science and Technology. 2008, № 6, p. 114-116.

12. K.V. Lotov, V.I. Maslov, I.N. Onishchenko. Long sequence of relativistic electron bunches as a driver in wakefield method of charged particles acceleration in plasma // Problems of Atomic Science and Technology. 2010, № 6, p. 103-107.

13. K.V. Lotov, V.I. Maslov, I.N. Onishchenko, M.S. Vesnovskaya. 2d3v Numerical simulation of instability of cylindrical relativistic electron beam in plasma // Problems of Atomic Science and Technology. 2010, № 4, p. 12-16.

14. K.V. Lotov, V.I. Maslov, I.N. Onishchenko, and E.N. Svistun. Homogeneous Focusing of Electron Bunch Sequence by Plasma Wakefield // Problems of Atomic Science and Technology. 2012, № 31, p. 59-63.

15. V.I. Maslov, I.N. Onishchenko, I.P. Yarovaya. Plasma Wakefield Excitation, Possessing of Homogeneous Focusing of Electron Bunches // Problems of Atomic Science and Technology. 2013, № 1, p. 134-136.

16. V.I. Maslov, I.N. Onishchenko, I.P. Yarovaya. Fields excited and providing a uniform focusing of short relativistic electron bunches in plasma // East European Journal of Physics. 2014, v. 2, p. 92-95.

17. K.V. Lotov, V.I. Maslov, I.N. Onishchenko I.P. Yarovaya. Transformer Ratio at Interaction of 
Long Sequence of Electron Bunches with Plasma // Problems of Atomic Science and Technology. 2011, № 3, p. 87-91.

18. V.I. Maslov, I.N. Onishchenko, I.P. Yarovaya. Transformer Ratio at Excitation of Nonlinear Wakefield in Plasma by Shaped Sequence of Electron Bunches with Linear Growth of Charge // Problems of Atomic Science and Technology. 2012, № 4, p. 128-130.

19. V.I. Maslov, I.N. Onishchenko, and I.P. Yarovaya. Wakefield Excitation in Plasma by Sequence of Shaped Electron Bunches // Problems of Atomic Science and Technology. 2012, № 6, p. 161-63.

20. I.P. Levchuk, V.I. Maslov, I.N. Onishchenko. Transformation ratio at wakefield excitation by linearly shaped sequence of short relativistic electron bunches in plasma // Problems of Atomic Science and Technology. 2015, № 6, p. 37-41.

21. V.I. Maslov, I.N. Onishchenko. Transformation ratio at wakefield excitation in dielectric resonator accelerator by shaped sequence of electron bunches with linear growth of current // Problems of Atomic Science and Technology. 2013, № 4, p. 69-72.

22. K.V. Lotov, V.I. Maslov, I.N. Onishchenko. Transformation ratio in wakefield method of acceleration for sequence of relativistic electron bunches // Problems of Atomic Science and Technology. 2010, № 4, p. 85-89.

23. V.I. Maslov, I.P. Levchuk, I.N. Onishchenko. Focusing of relativistic electron bunches by nonresonant wakefield excited in plasma // Problems of Atomic Science and Technology. 2010, № 4, p. 120-123.

24. K.V. Lotov, V.I. Maslov, I.N. Onishchenko, and E.N. Svystun. 2.5D simulation of plasma wakefield excitation by a nonresonant chain of relativistic electron bunches // Problems of Atomic Science and Technology. 2010, № 2, p. 122-24.

25. K.V. Lotov, V.I. Maslov, I.N. Onishchenko, and I.P. Yarovaya. Mechanisms of Synchronization of Relativistic Electron Bunches at Wakefield Excitation in Plasma // Problems of Atomic Science and Technology. 2013, № 4, p. 73-76.

26. Ya. Fainberg, M. Ayzatsky, V. Balakirev, et al. Focusing of Relativistic Electron Bunches at the Wakefield Excitation in Plasma // Proc. PAC'97. 12-16 May, 1997 Vancouver, Canada. V. II, p. 651-653.
27. C. O'Connell et al. Dynamic focusing of an electron beam through a long plasma // Phys. Rev. ST Accel. Beams. 2002, v. 5, p. 121301.

28. M.C. Tompson et al. CP877 // Adv. Accel. Concepts 12 Workshop. 2006, p. 561.

29. M.C. Tompson et al. Observations of low-aberration plasma lens focusing of relativistic electron beams at the underdense threshold // Phys. Plasmas. 2010, v. 17, p. 073105.

30. S. Yu. Kalmykov et al. Injection, trapping, and acceleration of electrons in a three-dimensional nonlinear laser wakefield // Phys. Plas. 2006, v. 13, p. 113102.

31. M.J. Hogan, C.E. Clayton, C. Huang, et al. Ultrarelativistic-Positron-Beam Transport through MeterScale Plasmas // Phys. Rev. Lett. 2003, v. 90(20), p. 205002.

32. P. Muggli, B.E. Blue, C.E. Clayton, et al. Halo Formation and Emittance Growth of Positron Beams in Plasmas // Phys. Rev. Lett. 2008, v. 101, p. 055001.

33. M. Reiser, H. Li. Solutions of the matched KV envelope equations for a "smooth" asymmetric focusing channel // J. Appl. Phys. 2004, v. 96 (№ 1), p. 784-790.

34. I. L. Sheynman, A. Kanareykin. Definition of Focusing System Parameters on the Basis of the Analysis of a Transverse Bunch Dynamics in Dielectric Loaded Wakefield Accelerator // Proc. IPAC'10, Kyoto, Japan. 2009, p. 4416-4418.

35. A.J.W. Reitsma, V.V. Goloviznin, L.P.J. Kamp, T.J. Schep. Bunch Self-Focusing Regime of Laser Wakefield Acceleration with Reduced Emittance Growth // Phys. Rev. Lett. 2002, v. 88, p. 014802.

36. C.B. Schroeder, J.S. Wurtele. Particle Beam Stability in the Hollow Plasma Channel Wake Field Accelerator. CP569 // Advanced Accelerator Concepts: Ninth Workshop. 2000, p. 616-629.

37. J.B. Rosenzweig et al. Acceleration and Focusing of Electrons in Two-Dimensional Nonlinear Plasma Wake Fields // Phys. Rev. A. 1991, v. 44 (№ 10), p. R6190-R6192.

38. K.V. Lotov. Simulation of Ultrarelativistic Beam Dynamics in Plasma Wakefield Accelerator // Phys. Plasmas. 1998, v. 5 (№ 3), p. 785-791.

Article received 16.06.2021

\section{ПЛАЗМЕННАЯ ЛИНЗА ДЛЯ ЭЛЕКТРОННОГО И ПОЗИТРОННОГО ПУЧКОВ}

\section{Д.С. Бондарь, В.И. Маслов, И.Н. Онищенко, Р.Т. Овсянников}

Необходима фокусировка как электронных, так и позитронных сгустков в электрон-позитронных коллайдерах. При инжекции длинного сгустка электронов/позитронов в плазму образующаяся фокусирующая сила не однородна, а с некоторыми осцилляциями. Показано, что длинный позитронный сгусток после фокусировки разрушается быстрее, чем электронный сгусток за счет бетатронных колебаний и плазменных осцилляций.

\section{ПЛАЗМОВА ЛІНЗА ДЛЯ ЕЛЕКТРОННОГО І ПОЗИТРОННОГО ПУЧКІВ}

\section{Д.С. Бондарь, В.І. Маслов, І.М. Оніщенко, Р.Т. Овсянніков}

Необхідне фокусування як електронних, так і позитронних згустків в електрон-позитронних колайдерах. При інжекції довгого згустка електронів/позитронів у плазму утворювана фокусуюча сила не однорідна, а 3 деякими осциляціями. Показано, що довгий позитронний згусток після фокусування руйнується швидше, ніж електронний згусток за рахунок бетатронних коливань і плазмових осциляцій. 